\title{
Preoperative identification of neurosurgery patients with a high risk of in-hospital complications: a prospective cohort of 418 consecutive elective craniotomy patients
}

\author{
Elina Reponen, MD, ${ }^{1}$ Miikka Korja, MD, PhD, ${ }^{2,3}$ Tomi Niemi, MD, PhD, ${ }^{1}$ \\ Marja Silvasti-Lundell, MD, PhD, ${ }^{1}$ Juha Hernesniemi, MD, PhD, ${ }^{2}$ and Hanna Tuominen, MD, PhD ${ }^{1}$ \\ Departments of ${ }^{1}$ Anaesthesiology and Intensive Care Medicine, and ${ }^{2}$ Neurosurgery, Helsinki University Central Hospital, \\ Helsinki, Finland; and ${ }^{3}$ Australian School of Advanced Medicine, Sydney, New South Wales, Australia
}

\begin{abstract}
OBJECT Patients undergoing craniotomy are routinely assessed preoperatively, yet the role of these assessments in predicting outcome is poorly studied. This study aimed to identify preoperative factors predicting in-hospital outcome after cranial neurosurgery.

METHODS The study cohort consisted of 418 consecutive adults undergoing elective craniotomy for any intracranial lesion. Apart from the age criteria ( $\geq 18$ years), almost all patients were considered eligible for the study to increase external validity of the results. The studied preoperative assessments included various patient-related data, routine blood tests, American Society of Anesthesiologists (ASA) Physical Status Classification system, and a local modification of the ASA classification (Helsinki ASA classification). Adverse outcomes were in-hospital mortality, in-hospital systemic or infectious complications, and in-hospital CNS deficits. Resource use was defined as length of stay (LOS) in the intensive care unit and overall LOS in the hospital.
\end{abstract}

RESULTS The in-hospital mortality rate was $1.0 \%$. In-hospital systemic or infectious complications and permanent or transient CNS deficits occurred in $6.7 \%$ and $11.2 \%$ of the patients, respectively. Advanced age ( $\geq 60-65$ years), elevated C-reactive protein level (> $3 \mathrm{mg} / \mathrm{L}$ ), and high Helsinki ASA score (Class 4) were associated with in-hospital systemic and infectious complications, and a combination of these could identify one-fourth of the patients with postoperative complications. Moreover, this combination of preoperative assessment parameters was significantly associated with increased resource use.

CONCLUSIONS In this first prospective and unselected cohort study of outcome after elective craniotomy, simple preoperative assessments identified patients with a high risk of in-hospital systemic or infectious complications as well as extended resource use. Presented risk assessment methods may be widely applicable, also in low-volume centers, as they are based on composite predictors and outcome events.

http://thejns.org/doi/abs/10.3171/2014.11.JNS141970

KEY WORDS craniotomy; elective; outcome; preoperative assessment

$\mathrm{D}$ UE to the increasing awareness and demand for improving the value of care - that is, the patient's outcome relative to the cost of care-the frequency and predictors of complications have become of significant interest to health care providers. The American Society of Anesthesiologists (ASA) Physical Status Classification system is the most well-known preoperative risk estimate used for surgical patients worldwide, ${ }^{3,4}$ but more customized risk prediction scores have emerged in a few subspecialties of major surgery, including cardiac surgery. ${ }^{7}$ The risk predicting the value of the ASA class has not been confirmed in cranial neurosurgery, and no customized risk scores exist. ${ }^{9}$ A recent large registry-based study with more than 38,000 neurosurgical patients $(10,041$ cranial neurosurgery patients) examined the frequency and predictors of complications in the United States from 2006

ABBREVIATIONS ASA = American Society of Anesthesiologists; $B M I=$ body mass index; $C R P=C$-reactive protein; $I C U$ = intensive care unit; LOS = length of stay; PT = prothrombin time.

SUBMITTED August 26, 2014. ACCEPTED November 7, 2014.

INCLUDE WHEN CITING Published online May 1, 2015; DOI: 10.3171/2014.11.JNS141970.

DISCLOSURE This work was supported by personal grants awarded by the Sigrid Jusélius Foundation, Biomedicum Helsinki Foundation, Orion-Farmos Research Foundation, Finnish Medical Foundation and Instrumentarium Research Foundation (to M.K.); the Finnish Society of Anaesthesiologists and Finnish Medical Association (to E.R.); and the Maire Taponen Foundation (to H.T.). 
to $2011 .{ }^{10}$ This retrospective study could not assess the role of routine preoperative blood tests, ASA class, or any other preoperative risk score in outcome prediction. Furthermore, the reliability of predicting outcomes by using registry-based data has been questioned by others ${ }^{5}$ and even by the authors themselves,,$^{10}$ specifically since in many large registries detailed preoperative patient data are lacking. Another major problem is that the type and rate of complications in neurosurgery are variable but limited. Thus, single predictors cannot reliably predict single complications. ${ }^{5}$

A traditional view suggests that in cranial neurosurgery, primarily the location and nature of the lesion together with the surgeon's expertise determine the risk of adverse outcome. However, if adverse outcome in cranial neurosurgery is seen more as a multifactorial entity, objective and patient-related parameters of physical status can have an effect on the short-term outcome. Evidence supporting the use of any preoperative risk assessment scores for predicting outcome in a consecutive series of elective craniotomy patients is lacking. ${ }^{9}$ In an attempt to bridge this gap in knowledge, we aimed to define a composite of prospectively recorded factors, all routinely recorded in preoperative anesthesia assessments, which could be used in predicting short-term outcome and resource use after elective cranial neurosurgery.

\section{Methods \\ Study Setting}

This study was reviewed and approved by the ethics committee of the Hospital District of Helsinki and Uusimaa. All subjects signed a written informed consent.

We collected a consecutive series of patients undergoing elective craniotomy in the Department of Neurosurgery, Helsinki University Central Hospital, between December 7, 2011, and December 31, 2012. Helsinki University Central Hospital is a public high-volume hospital complex with a neurosurgical department with more than 3200 operations annually. Finland has a publicly funded health care system, which offers social and health care for all citizens (http://www.stm.fi/en/social_and_health_ services/health_services). In general, all craniotomies are performed in one of the 5 public university hospitals in Finland. Helsinki University Central Hospital is the largest of these 5 university hospitals, and its catchment area has nearly 2 million people.

\section{Study Population}

Adult ( $\geq 18$ years) patients scheduled for elective cranial operations under general anesthesia were eligible to participate in the study. Elective craniotomy was defined as a craniotomy performed no earlier than 7 days after the treatment decision. Exclusion criteria included 1) a lack of fluency in Finnish or Swedish (the official languages in Finland), 2) age younger than 18 years, 3) epilepsy as an indication for craniotomy (implantations of electrode grids for electrocorticographic recordings and subsequent resections of epileptogenic zones), or 4) inability to communicate because of severe underlying illness or advanced cognitive dysfunction. Patients with multiple elective cra- niotomies during the study period were enrolled only once at the time of the first craniotomy.

\section{Data Collection}

Preoperative radiological imaging studies as well as consultations with anesthesiologists and neurosurgeons adhered to the department's standard practice. Anesthesia, surgery, and postoperative care in the neurosurgical intensive care unit (ICU) also followed the normal routines and protocols of the department. In brief, the overall treatment was unaffected by this study. Since most of the medical data during the hospital stay are routinely recorded into electronic hospital databases and patient records, we retrieved all relevant and additional patient data from these sources when necessary.

\section{Preoperative Patient-Related Data}

Anesthesiologists or neurosurgical nurses recorded data on age, sex, weight, height, body mass index (BMI), systolic blood pressure, diastolic blood pressure, and heart rate 1-30 days before the operation at the neurosurgical ward or at a preoperative outpatient clinic.

\section{Preoperative ASA Classes}

During the preoperative assessment, one of the anesthesiologist authors determined the ASA class according to the original ASA criteria and also according to a local modification of the ASA (Helsinki ASA) criteria (Table 1). The Helsinki ASA classification was implemented into clinical use at our institution in the 1990s. The neuroanesthesiologists considered the modification essential due to the clinic's patient profile with emphasis on intracranial vascular surgery. The Helsinki ASA classification system has not been validated and was not modified for the purposes of this study.

\section{Preoperative Blood Tests}

Preoperative blood tests followed the normal routines and protocols of the unit and included hemoglobin, platelets, creatinine, blood glucose (not fasting), C-reactive protein (CRP), sodium, potassium, and prothrombin time (PT). These blood tests took place within 1 week before the clinical preoperative assessment.

\section{Follow-Up Data}

Before discharge from the study hospital, one of the authors recorded the in-hospital mortality, systemic and infectious complications, and CNS deficits.

\section{End Points}

Adverse outcomes and resource use were chosen as end points. Adverse outcomes included in-hospital mortality, in-hospital systemic and infectious complications (deep vein thrombosis, pulmonary embolism, acute myocardial infarction, new ventricular arrhythmias, cardiogenic shock, cardiac arrest, pneumonia, meningitis, sepsis), and in-hospital CNS deficits (a new or worsened hemiparesis, stroke [clinical and/or radiological]; transient or permanent). Resource use was defined as length of stay (LOS) in the ICU and hospital. 
TABLE 1. American Society of Anesthesiologists Physical Status Classification and its modifications

\begin{tabular}{|c|c|c|c|c|}
\hline \multirow{2}{*}{$\begin{array}{l}\text { ASA } \\
\text { Class }\end{array}$} & \multicolumn{4}{|c|}{ ASA Classification System } \\
\hline & $1941^{*}$ & 1962/1963† & Today $\ddagger$ & Helsinki ASA \\
\hline 1 & $\begin{array}{l}\text { "No organic pathology or patients in whom the patho- } \\
\text { logical process is localized and does not cause any } \\
\text { systemic disturbance or abnormality." }\end{array}$ & "A normal healthy patient." & $\begin{array}{l}\text { "A normal healthy } \\
\text { patient" }\end{array}$ & $\begin{array}{l}\text { A previously healthy patient, age } \\
<65 \text { years }\end{array}$ \\
\hline 2 & $\begin{array}{l}\text { "A moderate but definite systemic disturbance, caused } \\
\text { either by the condition that is to be treated by surgi- } \\
\text { cal intervention or which is caused by other existing } \\
\text { pathological process, forms this group." }\end{array}$ & $\begin{array}{l}\text { "A patient with a mild } \\
\text { systemic disease." }\end{array}$ & $\begin{array}{l}\text { "A patient with mild } \\
\text { systemic disease" }\end{array}$ & $\begin{array}{l}\text { A previously healthy, age } \geq 65 \\
\text { years } \\
\text { A patient with mild systemic } \\
\text { disease }\end{array}$ \\
\hline 3 & $\begin{array}{l}\text { "Severe systemic disturbance from any cause or } \\
\text { causes. It is not possible to state an absolute } \\
\text { measure of severity, as this is a matter of clinical } \\
\text { judgment." }\end{array}$ & $\begin{array}{l}\text { "A patient with a severe } \\
\text { systemic disease that } \\
\text { limits activity, but is not } \\
\text { incapacitating." }\end{array}$ & $\begin{array}{l}\text { "A patient with } \\
\text { severe systemic } \\
\text { disease" }\end{array}$ & $\begin{array}{l}\text { A patient with severe systemic } \\
\text { disease } \\
\text { A previously healthy patient }<65 \\
\text { years, who has a small unrup- } \\
\text { tured intracranial aneurysm } \\
\text { or a small brain tumor with no } \\
\text { symptoms/mild symptoms }\end{array}$ \\
\hline 4 & $\begin{array}{l}\text { "Extreme systemic disorders which have already } \\
\text { become an eminent threat to life regardless of the } \\
\text { type of treatment. Because of their duration or nature } \\
\text { there has already been damage to the organism that } \\
\text { is irreversible. This class is intended to include only } \\
\text { patients that are in an extremely poor physical state. } \\
\text { There may not be much occasion to use this clas- } \\
\text { sification, but it should serve a purpose in separating } \\
\text { the patient in very poor condition from others." }\end{array}$ & $\begin{array}{l}\text { "A patient with an incapac- } \\
\text { itating systemic disease } \\
\text { that is a constant threat } \\
\text { to life." }\end{array}$ & $\begin{array}{l}\text { "A patient with } \\
\text { severe systemic } \\
\text { disease that is a } \\
\text { constant threat } \\
\text { to life" }\end{array}$ & $\begin{array}{l}\text { A patient with unbalanced sys- } \\
\text { temic disease } \\
\text { A previously healthy patient with } \\
\text { a clearly symptomatic intracra- } \\
\text { nial aneurysm or brain tumor }\end{array}$ \\
\hline 5 & $\begin{array}{l}\text { "Emergencies that would otherwise be graded in Class } \\
1 \text { or Class 2." }\end{array}$ & $\begin{array}{l}\text { "A moribund patient not } \\
\text { expected to survive } 24 \\
\text { hours with or without } \\
\text { operation." }\end{array}$ & $\begin{array}{l}\text { "A moribund } \\
\text { patient who is } \\
\text { not expected to } \\
\text { survive without } \\
\text { the operation" }\end{array}$ & $\begin{array}{l}\text { A moribund patient who is not } \\
\text { expected to survive without } \\
\text { the operation }\end{array}$ \\
\hline 6 & $\begin{array}{l}\text { "Emergencies that would otherwise be graded in Class } \\
3 \text { or Class 4" }\end{array}$ & & $\begin{array}{l}\text { "A declared brain- } \\
\text { dead patient } \\
\text { whose organs are } \\
\text { being removed for } \\
\text { donor purposes" }\end{array}$ & \\
\hline$E$ & & $\begin{array}{l}\text { "In the event of emergency } \\
\text { procedure, precede the } \\
\text { number with an E." }\end{array}$ & & \\
\hline
\end{tabular}

\section{Statistical Analyses}

Given the principal idea of defining a new combination of outcome predictors instead of single independent outcome predictors, we categorized continuous variables to quartiles. The Kruskal-Wallis test provided means of comparing differences between these quartiles. The MannWhitney test permitted post hoc comparisons of each pair in groups after significant Kruskal-Wallis tests. We also used the Kruskal-Wallis test to see if there were differences between ASA scores and resource use (LOS), and for comparing differences in the sum of the ranks of continuous variables between patients with and without adverse outcomes. The Pearson chi-square test or Fisher's exact test (cell count $\leq 5$ ) was used to used categorical variables related to dichotomized outcome. The Pearson chi-square test with $2 \times 2$ contingency tables enabled the calculation of odds ratios with $95 \%$ confidence intervals, sensitivity, specificity, positive predictive value, and negative predictive value. Even though it was not our goal to identify single independent predictors, we also performed multivariable regression analyses. In all tests, $\mathrm{p}$ values $<0.05$ were considered significant. The statistical analyses were carried out using IBM SPSS 21.0 statistical software for Mac OS X (version 21.0) and for Windows (version 21.0).

\section{Results}

A total of 644 patients underwent an elective craniotomy during the study period of nearly 13 months. The final study cohort consisted of 418 (75.9\%) of 551 eligible 
patients. The details on patient enrollment are presented in the study flow chart (Fig. 1).

\section{Patient Characteristics}

The mean and median ages of the 418 patients were 56.4 (SD 13.9 years) and 58.0 years (range 18 to 87 years), respectively, and $260(62.2 \%)$ patients were female. In 124 cases (29.7\%), patients were 65 years or older.

\section{Craniotomies}

The most common indications were a vascular lesion (for example, an aneurysm or arteriovenous malformation) in 138 (33.0\%), a benign tumor in 134 (32.1\%), and a malignant tumor in 121 (28.9\%) of the 418 operations. The mean and median operation times (defined as the period from the time of the surgeon's first intervention, e.g., beginning of the sterile preparation until completion of the wound dressings) were 2 hours 40 minutes (SD 91.6 minutes) and 2 hours 8 minutes (range 42-767 minutes), respectively.
The mean and median general anesthesia times (defined as the time from the beginning of the administration of the first anesthetic agent until extubation or transfer to the ICU) were 3 hours 16 minutes (SD 93.2 minutes) and 2 hours 42 minutes (range 52-794 minutes), respectively. After the surgery, $57.3 \%$ of the extubations occurred in the operating room, and the remaining extubations took place in the ICU. For logistic reasons, transferring patients to the ICU before extubation is common at our clinic even in the case of uncomplicated surgical care or the absence of patient-related factors requiring prolonged intubation. Of all the patients, $94.7 \%$ were extubated within 6 hours after the end of surgery.

\section{End Points}

The in-hospital mortality rate was $1.0 \%$ (4 of 418 patients). In-hospital systemic or infectious complications occurred in $28(6.7 \%)$ of 418 patients. In-hospital permanent or transient CNS deficits were recorded in 47 (11.2\%)

\section{4 elective craniotomy patients between $12 / 7 / 2011$ and \\ $12 / 31 / 2012$}

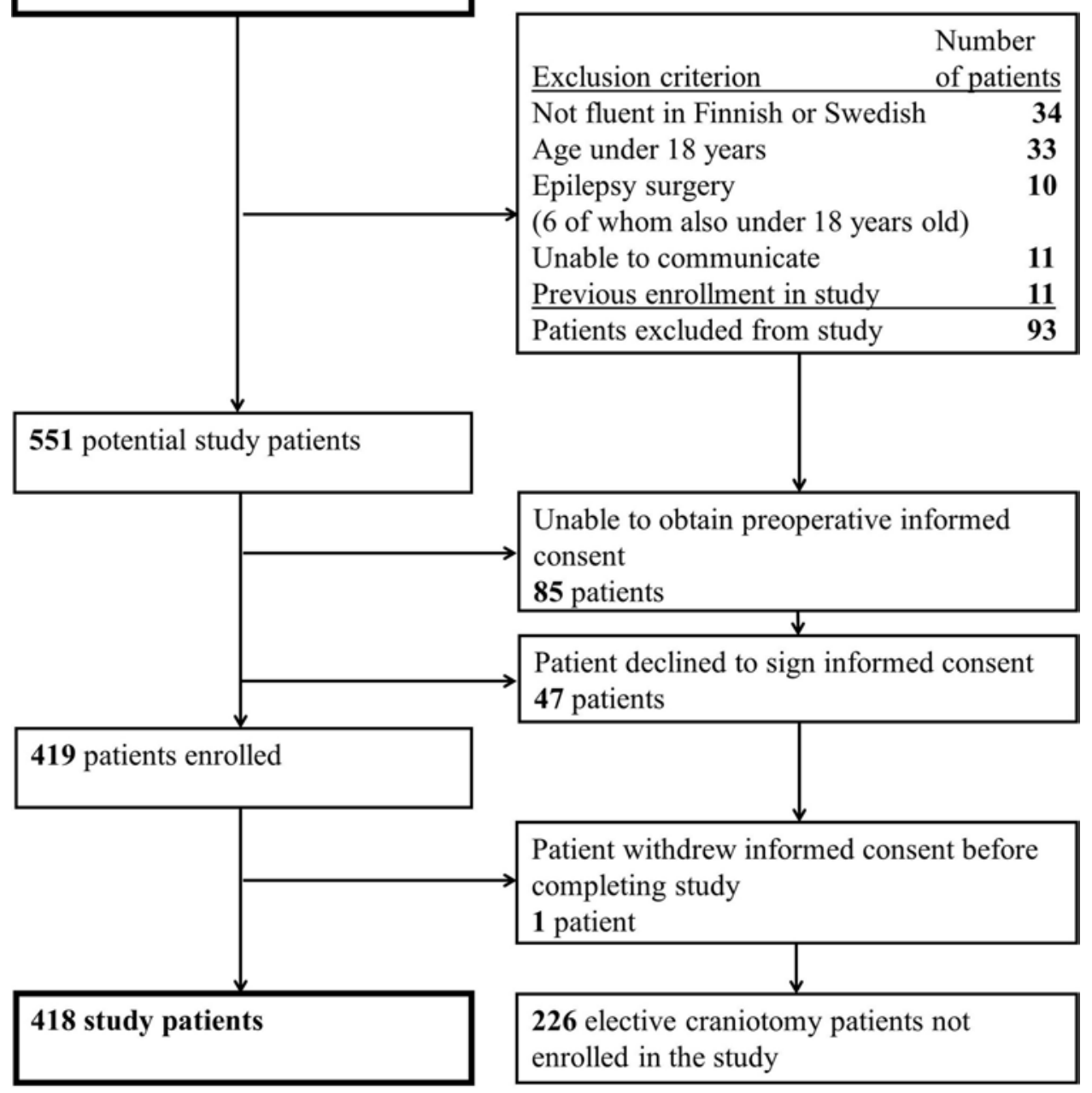

FIG. 1. Flow chart of patient enrollment in the study. 
TABLE 2. LOSs in the ICU and the hospital in all study patients, patients with systemic and infectious complications, and patients with CNS deficits

\begin{tabular}{lcc}
\hline \multicolumn{1}{c}{ Patients } & $\begin{array}{c}\text { Mean ICU LOS } \\
\text { in Days }\end{array}$ & $\begin{array}{c}\text { Mean Hospital } \\
\text { LOS in Days }\end{array}$ \\
\hline All $(n=418)$ & & \\
\hline Mean \pm SD & $1.3 \pm 1.4$ & $5.6 \pm 3.5$ \\
\hline Median (range) & $1.0(0-13)$ & $5.0(1-34)$ \\
\hline $\begin{array}{l}\text { Systemic \& infectious complications } \\
(n=28)\end{array}$ & & \\
\hline Mean \pm SD & $2.9 \pm 3.5$ & $9.8 \pm 7.8$ \\
\hline Median (range) & $1.0(0-13)$ & $7.5(2-34)$ \\
\hline CNS deficits ( $=47)$ & & \\
\hline Mean \pm SD & $2.7 \pm 3.5$ & $7.0 \pm 3.8$ \\
\hline Median (range) & $1.0(1-13)$ & $6.0(2-17)$ \\
\hline
\end{tabular}

of 418 patients. Table 2 provides the ICU LOS and overall hospital LOS for all study patients and in the complication groups. Overall, $90.9 \%$ of the patients stayed 24 hours or less in the ICU. Most of the patients (84.7\%) were discharged within the 1st postoperative week.

\section{Single End Point Predictors in Univariate Analyses Mortality}

Given the limited number of in-hospital deaths (4 patients), no reliable predictors for mortality could be calculated. However, all 4 in-hospital deaths occurred in patients older than 65 years with a preoperative Helsinki ASA class of 3 or higher.

\section{Morbidity}

Older age (Tables 3-5), increased CRP (> $3 \mathrm{mg} / \mathrm{L}$ ) (Tables 3 and 5), and the Helsinki ASA class (Table 5) were associated with in-hospital systemic and infectious complications. Patients with BMI values between 25.8 and 29.0 had more in-hospital systemic and infectious complications than patients in the lowest and highest quartiles (Table 4). No preoperative variable correlated with inhospital permanent or transient CNS deficits (Tables 3-5).

\section{Resource Use}

Age $\geq 65$ years and high Helsinki ASA class $(>2)$ were associated with increased resource use (Table 5). The oldest age group (66-87 years) stayed on average 1 day longer in the hospital than the youngest age group (18-47 years) (Table 6). Patients with preoperative blood glucose levels $\geq 6.7 \mathrm{mmol} / \mathrm{L}$ had a longer LOS in the ICU than patients with levels $\leq 5.7 \mathrm{mmol} / \mathrm{L}$ (Table 6). Patients with lowest (2.9-3.7 $\mathrm{mmol} / \mathrm{L})$ and highest $(4.2-5.6 \mathrm{mmol} / \mathrm{L})$ potassium levels also stayed longer in the ICU than patients with potassium levels 4.0 to $4.1 \mathrm{mmol} / \mathrm{L}$ (Table 6). Moreover, patients with the lowest hemoglobin levels (105-133 g/L) and patients with the highest systolic blood pressure values (156-224 $\mathrm{mm} \mathrm{Hg}$ ) seemed to be discharged marginally later than most of the other patients in the same group (Table 6).

\section{Single End Point Predictors in Multivariable Analyses}

Multivariable logistic regression analyses were conducted using variables that were found to be significant in the univariate analyses for morbidity (age, CRP, BMI, and Helsinki ASA class) and resource use (age, Helsinki ASA

TABLE 3. Preoperative patient-related factors, routine blood tests, and in-hospital outcome*

\begin{tabular}{|c|c|c|c|c|c|c|c|}
\hline \multirow[b]{2}{*}{ Factor } & \multirow{2}{*}{$\begin{array}{c}\text { No. of } \\
\text { Patients }\end{array}$} & \multicolumn{2}{|c|}{ Systemic \& Infectious Complications } & \multirow[b]{2}{*}{ p Value } & \multicolumn{2}{|c|}{ New CNS Deficits } & \multirow[b]{2}{*}{$\mathrm{p}$ Value } \\
\hline & & Yes (range) & No (range) & & Yes (range) & No (range) & \\
\hline Age (yrs) & 418 & $64(29-87)$ & $56(18-85)$ & 0.002 & $58(26-80)$ & $56(18-87)$ & 0.138 \\
\hline Males & 418 & $8.9 \%$ & $91.1 \%$ & \multirow{2}{*}{0.168} & $13.9 \%$ & $86.1 \%$ & \multirow{2}{*}{0.176} \\
\hline Females & 418 & $5.4 \%$ & $94.6 \%$ & & $9.6 \%$ & $90.4 \%$ & \\
\hline Weight (kg) & 417 & $77(52-107)$ & $77(40-164)$ & 0.448 & $74(44-164)$ & $77(40-155)$ & 0.255 \\
\hline Height (cm) & 416 & $172(150-187)$ & $169(148-205)$ & 0.176 & $170(55-187)$ & $169(148-205)$ & 0.832 \\
\hline BMI & 416 & $26(19-33)$ & $27(16-47)$ & 0.943 & $26(17-47)$ & $27(16-45)$ & 0.140 \\
\hline $\mathrm{SBP}(\mathrm{mm} \mathrm{Hg})$ & 416 & $140(104-197)$ & $143(95-224)$ & 0.400 & 147 (108-201) & $142(95-224)$ & 0.066 \\
\hline $\mathrm{DBP}(\mathrm{mm} \mathrm{Hg})$ & 416 & $85(57-112)$ & $86(46-137)$ & 1.00 & $87(60-112)$ & $86(46-137)$ & 0.270 \\
\hline HR (per min) & 415 & $71(47-111)$ & $70(41-114)$ & 0.722 & $72(49-97)$ & $70(41-114)$ & 0.209 \\
\hline $\mathrm{Hb}(\mathrm{g} / \mathrm{L})$ & 417 & 137 (105-157) & 141 (106-180) & 0.509 & 140 (105-172) & 141 (106-180) & 0.937 \\
\hline Platelets (109/L) & 417 & $241(104-543)$ & $246(32-498)$ & 0.308 & $247(82-543)$ & 245 (32-498) & 0.994 \\
\hline Crea ( $\mu \mathrm{mol} / \mathrm{L})$ & 416 & 74 (43-107) & $70(5-160)$ & 0.102 & $68(43-108)$ & $70(5-160)$ & 0.408 \\
\hline Gluc (mmol/L) & 409 & $6.4(4.6-10.5)$ & $6.5(3.9-24.8)$ & 0.393 & $7.0(4.5-24.5)$ & $6.4(3.9-24.8)$ & 0.151 \\
\hline CRP (mg/L) & 412 & $5.5(3-16)$ & $5.1(3-77)$ & 0.034 & $4.4(3-25)$ & $5.2(3-77)$ & 0.816 \\
\hline $\mathrm{Na}(\mathrm{mmol} / \mathrm{L})$ & 417 & $139(126-146)$ & $138(123-158)$ & 0.438 & 138 (127-146) & $139(123-158)$ & 0.912 \\
\hline $\mathrm{K}(\mathrm{mmol} / \mathrm{L})$ & 417 & $4.1(3.4-5.1)$ & $4.0(2.9-5.6)$ & 0.068 & $4.0(3.1-4.8)$ & $4.0(2.9-5.6)$ & 0.423 \\
\hline PT (\%) & 410 & $109(37-152)$ & $112(9-170)$ & 0.591 & $111(37-166)$ & $112(9-170)$ & 0.965 \\
\hline
\end{tabular}

Crea = plasma creatinine; $\mathrm{DBP}=$ diastolic blood pressure; Gluc = blood glucose (not fasting); $\mathrm{Hb}=$ plasma hemoglobin; $\mathrm{HR}=$ heart rate; $\mathrm{K}=$ plasma potassium; $\mathrm{Na}=$ plasma sodium; $\mathrm{SBP}=$ systolic blood pressure.

* Mean values are reported for continuous variables. The Mann-Whitney test was used for all variables except for sex, which was studied using the Pearson chi-square test. Values in boldface are statistically significant. 
TABLE 4. Preoperative patient-related factors, routine blood tests, and in-hospital outcome*

\begin{tabular}{|c|c|c|c|c|c|}
\hline Factor & No. of Patients & Systemic \& Infectious Complications (\%) & $\mathrm{p}$ Value & CNS Complications (\%) & $\mathrm{p}$ Value \\
\hline Age (yrs) & 418 & & $0.014 \dagger$ & & 0.343 \\
\hline $18-47$ & 105 & $2(1.9)$ & & $10(9.5)$ & \\
\hline $48-58$ & 110 & $6(5.5)$ & & $9(8.2)$ & \\
\hline $59-65$ & 93 & $6(6.5)$ & & $11(11.8)$ & \\
\hline $66-87$ & 110 & $14(12.7)$ & & $17(15.5)$ & \\
\hline Sex & 418 & & 0.168 & & 0.176 \\
\hline Male & 158 & $14(8.9)$ & & $22(13.9)$ & \\
\hline Female & 260 & $14(5.4)$ & & $25(9.6)$ & \\
\hline Weight (kg) & 417 & & 0.454 & & 0.596 \\
\hline $40-64$ & 97 & $5(5.2)$ & & $12(12.4)$ & \\
\hline $65-74$ & 113 & $5(4.4)$ & & $13(11.5)$ & \\
\hline $75-86$ & 104 & $9(8.7)$ & & $14(13.5)$ & \\
\hline $87-164$ & 103 & $9(8.7)$ & & $8(7.8)$ & \\
\hline Height (cm) & 416 & & 0.105 & & 0.549 \\
\hline 148-162 & 115 & $7(6.1)$ & & $15(13.0)$ & \\
\hline $163-169$ & 96 & $2(2.1)$ & & $7(7.3)$ & \\
\hline $170-176$ & 102 & $8(7.8)$ & & $13(12.7)$ & \\
\hline 177-205 & 103 & $11(10.7)$ & & $12(11.7)$ & \\
\hline BMI & 416 & & $0.024 \ddagger$ & & 0.193 \\
\hline $16.4-23.4$ & 103 & $4(3.9)$ & & $14(13.6)$ & \\
\hline $23.5-25.7$ & 105 & $8(7.6)$ & & $12(11.4)$ & \\
\hline $25.8-29.0$ & 104 & $13(12.5)$ & & $15(14.4)$ & \\
\hline $29.1-47.4$ & 104 & $3(2.9)$ & & $6(5.8)$ & \\
\hline $\mathrm{SBP}(\mathrm{mm} \mathrm{Hg})$ & 416 & & 0.842 & & 0.063 \\
\hline 95-128 & 106 & $9(8.5)$ & & $9(8.5)$ & \\
\hline $129-141$ & 103 & $6(5.8)$ & & $9(8.7)$ & \\
\hline $142-155$ & 105 & $6(5.7)$ & & $10(9.5)$ & \\
\hline $156-224$ & 102 & $7(6.9)$ & & $19(18.6)$ & \\
\hline $\mathrm{DBP}(\mathrm{mm} \mathrm{Hg})$ & 416 & & 0.615 & & 0.700 \\
\hline $46-78$ & 101 & $8(7.9)$ & & $10(9.9)$ & \\
\hline $79-86$ & 113 & $5(4.4)$ & & $11(9.7)$ & \\
\hline $87-93$ & 105 & $9(8.6)$ & & $12(11.4)$ & \\
\hline $94-137$ & 97 & $6(6.2)$ & & $14(14.4)$ & \\
\hline HR (per min) & 415 & & 0.542 & & 0.387 \\
\hline $41-60$ & 106 & $6(5.7)$ & & $9(8.5)$ & \\
\hline $61-68$ & 102 & $7(6.9)$ & & $11(10.8)$ & \\
\hline $69-78$ & 104 & $10(9.6)$ & & $10(9.6)$ & \\
\hline $79-114$ & 103 & $5(4.9)$ & & $16(15.5)$ & \\
\hline $\mathrm{Hb}(\mathrm{g} / \mathrm{L})$ & 417 & & 0.841 & & 0.708 \\
\hline 105-133 & 108 & $8(7.4)$ & & $14(13.0)$ & \\
\hline $134-140$ & 100 & $7(7.0)$ & & $8(8.0)$ & \\
\hline $141-147$ & 104 & $5(4.8)$ & & $12(11.5)$ & \\
\hline $148-180$ & 105 & $8(7.6)$ & & $12(11.4)$ & \\
\hline Platelets (109/L) & 417 & & 0.349 & & 0.400 \\
\hline $32-201$ & 104 & $6(5.8)$ & & $14(13.5)$ & \\
\hline $202-238$ & 105 & $11(10.5)$ & & $7(6.7)$ & \\
\hline $239-285$ & 103 & $6(5.8)$ & & $13(12.6)$ & \\
\hline $286-543$ & 105 & $5(4.8)$ & & $12(11.4)$ & \\
\hline
\end{tabular}


TABLE 4. Preoperative patient-related factors, routine blood tests, and in-hospital outcome* (continued)

\begin{tabular}{|c|c|c|c|c|c|}
\hline Factor & No. of Patients & Systemic \& Infectious Complications (\%) & $p$ Value & CNS Complications (\%) & $\mathrm{p}$ Value \\
\hline Crea $(\mu \mathrm{mol} / \mathrm{L})$ & 416 & & 0.290 & & 0.428 \\
\hline $5-59$ & 104 & $5(4.8)$ & & $15(14.4)$ & \\
\hline $60-68$ & 106 & $5(4.7)$ & & $10(9.4)$ & \\
\hline $69-77$ & 102 & $7(6.9)$ & & $8(7.8)$ & \\
\hline $78-160$ & 104 & $11(10.6)$ & & $13(12.5)$ & \\
\hline Gluc (mmol/L) & 409 & & 0.701 & & 0.337 \\
\hline $3.9-5.3$ & 111 & $5(4.5)$ & & $10(9.1)$ & \\
\hline $5.4-5.7$ & 87 & $6(6.9)$ & & $9(10.3)$ & \\
\hline $5.8-6.6$ & 105 & $7(6.1)$ & & $10(9.5)$ & \\
\hline $6.7-24.8$ & 106 & $9(9.3)$ & & $17(16.0)$ & \\
\hline $\mathrm{Na}(\mathrm{mmol} / \mathrm{L})$ & 417 & & 0.077 & & 0.842 \\
\hline $123-136$ & 92 & $8(8.7)$ & & $10(10.9)$ & \\
\hline $137-139$ & 143 & $4(2.8)$ & & $14(9.8)$ & \\
\hline 140 & 56 & $3(5.4)$ & & $8(14.3)$ & \\
\hline $141-148$ & 126 & $13(10.3)$ & & 14 (11.1) & \\
\hline $\mathrm{K}(\mathrm{mmol} / \mathrm{L})$ & 417 & & 0.178 & & 0.297 \\
\hline 2.9-3.7 & 91 & $5(5.5)$ & & 14 (15.4) & \\
\hline $3.8-3.9$ & 106 & $5(4.7)$ & & $11(10.4)$ & \\
\hline $4.0-4.1$ & 102 & $5(4.9)$ & & $7(6.9)$ & \\
\hline $4.2-5.6$ & 118 & $13(11.0)$ & & $14(11.9)$ & \\
\hline PT (\%) & 410 & & 0.645 & & 0.715 \\
\hline $9-96$ & 104 & $8(7.7)$ & & $9(8.7)$ & \\
\hline $97-108$ & 103 & $8(7.8)$ & & $14(13.6)$ & \\
\hline $109-128$ & 100 & $4(4.0)$ & & $12(12.0)$ & \\
\hline $129-170$ & 103 & $8(7.8)$ & & $11(10.7)$ & \\
\hline
\end{tabular}

class, systolic blood pressure, hemoglobin, glucose, and potassium). For systemic and infectious complications, CRP remained significant after bivariate logistic regression analyses only when treated as a categorized (dichotomized) covariate, whereas age retained its significance whether treated as a categorical or a continuous covariate (results not shown). Helsinki ASA classification (categorical) also remained significant in all possible multivariable regression analyses (results not shown). Using linear regression analyses for continuous outcome variables, Helsinki ASA classification (categorical) was the only variable that remained a significant predictor for both ICU LOS and hospital LOS (results not shown).

\section{Composite End Point Predictor}

Various combinations of significant end point predictors were evaluated for the identification of high-risk patients for complications and increased resource use (results not shown). Almost one-fourth of the patients with Helsinki ASA Class 4, age $\geq 60$ years, and CRP values $>3 \mathrm{mg} / \mathrm{L}$ had systemic or infectious complications after cranial surgery, with up to nearly 5 times higher odds ratios (Table
7). If a patient $\geq 60$ years had a preoperative Helsinki ASA class of 4 , the LOS in the ICU was nearly $40 \%$ and in hospital approximately 20\% longer than in patients without this combination of factors (Table 8).

\section{Discussion}

In this first prospective study on outcome predictors in an unselected cohort of patients undergoing cranial neurosurgery, higher Helsinki ASA class ( $>2)$, increased age (> 60-65 years) and abnormal CRP values (>3 mg/L) predicted postoperative in-hospital systemic and infectious complications. A composite factor of the Helsinki ASA class, age, and CRP value identified patients with up to nearly 5 times higher odds ratios for postoperative systemic and infectious complications preoperatively (Table 7). In other words, it was able to identify almost every fourth patient with major postoperative systemic or infectious complications (Table 7). The composite factor also predicted a prolonged stay in the ICU (Table 8). No preoperative assessment parameter predicted postoperative CNS complications, which probably are more lesion and surgeon-related complications than systemic and infectious 
TABLE 5. Major risk predictors and study end points*

\begin{tabular}{|c|c|c|c|c|c|c|c|c|c|c|c|}
\hline \multirow[b]{2}{*}{ Factor } & \multirow{2}{*}{$\begin{array}{c}\text { No. of } \\
\text { Patients (\%) }\end{array}$} & \multicolumn{2}{|c|}{ Systemic \& Infectious } & \multirow[b]{2}{*}{$p$ Value } & \multicolumn{2}{|c|}{ New CNS Deficits } & \multirow[b]{2}{*}{$p$ Value } & \multirow{2}{*}{$\begin{array}{l}\text { ICU LOS } \\
\text { (days) }\end{array}$} & \multirow[b]{2}{*}{$\mathrm{p}$ Value } & \multirow{2}{*}{$\begin{array}{l}\text { Hospital LOS } \\
\text { (days) }\end{array}$} & \multirow[b]{2}{*}{ p Value } \\
\hline & & Yes (\%) & No (\%) & & Yes $(\%)$ & No $(\%)$ & & & & & \\
\hline ASA class & & & & 0.213 & & & 0.408 & & 0.095 & & 0.389 \\
\hline 1 & $67(16.1)$ & $2(3.0)$ & $65(97.0)$ & & $7(10.4)$ & $60(89.6)$ & & 1.09 & & 5.12 & \\
\hline 2 & $152(36.5)$ & $8(5.3)$ & $144(94.7)$ & & $19(12.5)$ & $133(87.5)$ & & 1.42 & & 5.53 & \\
\hline 3 & $166(39.8)$ & $14(8.4)$ & $152(91.6)$ & & $15(9.0)$ & $151(91.0)$ & & 1.16 & & 5.64 & \\
\hline 4 & $32(7.7)$ & $4(12.5)$ & $28(87.5)$ & & $6(18.8)$ & $26(81.3)$ & & 1.84 & & 6.34 & \\
\hline Helsinki ASA class & & & & $0.021 \dagger$ & & & 0.663 & & $0.036 \ddagger$ & & $0.007 \S$ \\
\hline 1 & $4(1.0)$ & 0 & $4(100.0)$ & & 0 & $4(100.0)$ & & 1.0 & & 4.0 & \\
\hline 2 & $94(22.5)$ & $1(1.1)$ & $93(98.9)$ & & $9(9.6)$ & $85(90.4)$ & & 1.12 & & 4.82 & \\
\hline 3 & $251(60.2)$ & $18(7.2)$ & $233(92.8)$ & & 28 (11.2) & $223(88.8)$ & & 1.22 & & 5.65 & \\
\hline 4 & $68(16.3)$ & $9(13.2)$ & $59(86.8)$ & & $10(14.7)$ & $58(85.3)$ & & 1.87 & & 6.35 & \\
\hline Age in yrs & & & & 0.004 & & & 0.169 & & 0.027 & & 0.008 \\
\hline$\geq 65$ & $124(29.7)$ & $15(12.1)$ & $109(87.9)$ & & $18(14.5)$ & $106(85.5)$ & & 1.35 & & 6.06 & \\
\hline$<65$ & $294(70.3)$ & $13(4.4)$ & $281(95.6)$ & & $29(9.9)$ & $265(90.1)$ & & 1.28 & & 5.36 & \\
\hline CRP in $\mathrm{mg} / \mathrm{L}$ & & & & 0.046 & & & 0.835 & & 0.689 & & 0.889 \\
\hline$>3$ & $106(25.7)$ & $11(10.4)$ & 95 (89.6) & & $11(10.4)$ & 95 (89.6) & & 1.32 & & 5.60 & \\
\hline$\leq 3$ & $306(74.3)$ & $15(4.9)$ & $291(95.1)$ & & 34 (11.1) & $272(88.9)$ & & 1.25 & & 5.34 & \\
\hline
\end{tabular}

* The Pearson chi-square test was used for $2 \times 2$ and $2 \times k$ contingency tables of categorical variables. The Kruskal-Wallis test was used for studying differences in LOS. The post hoc Mann-Whitney test was used on each pair of significant groups. Values in boldface are statistically significant.

$\dagger$ ASA Helsinki Class 2 differed from ASA Helsinki Classes $3(p=0.027)$ and $4(p=0.002)$.

$\ddagger$ ASA Helsinki Class 4 differed from ASA Helsinki Classes $2(p=0.015)$ and $3(p=0.013)$.

$\S$ ASA Helsinki Class 2 differed from ASA Helsinki Classes $3(p=0.022)$ and $4(p=0.001)$.

complications. Focusing on the preoperative identification of patients susceptible to in-hospital complications was the rationale behind the decision not to focus and report on numerous other perioperative factors that may contribute to outcome, such as the choice of anesthetic agent, intraoperative temperature control, type of antibiotic prophylaxis, or postoperative analgesia. In brief, it is practically impossible to control all theoretical confounding factors in similar outcome studies. Furthermore, these results are in keeping with the findings based on the recent systematic review, suggesting that preoperative ASA class can be useful in predicting other than lesion and surgeon-related complications. ${ }^{9}$

\section{Role of Study Design and Clinical Applicability}

An era of big data analyses in health care has already started. Despite the potential benefits of the big data revolution, the value of any results relies on validity of the data used. When identifying new associations with surgical outcomes, most large registries and databases cannot provide us with detailed and useful results. In the recent retrospective study of more than 10,000 cranial neurosurgery patients, ${ }^{10}$ the incomplete reflection of patient characteristics obtained from the database as well as the lack of fit for the complications unique to neurosurgical patients hindered the identification of useful predictors for adverse outcome, as discussed by the authors. Furthermore, the reliability of evaluating the quality of care based on such registries is compromised by the rarity of outcome events along with the low caseload in many individual hospitals. ${ }^{5}$ Considering the low rates of morbidity and mortality in modern cranial neurosurgery, identifying single independent outcome predictors was beyond the scope of our study. Instead, we aimed to find a preoperative composite factor that should act as a red flag and suggest a more thorough evaluation and individually tailored perioperative plan for patients at high risk for postoperative systemic and infectious complications in an unselected cohort of patients undergoing elective cranial neurosurgery. Identifying a preoperative composite factor with a reasonable positive predictive value can be sensible even in low caseload units, since it seems unlikely that a single preoperative outcome predictor for all neurosurgical patients would be found.

\section{ASA Class and Composite Preoperative End Point Predictor}

The ASA Physical Status Classification system was first introduced in the 1940s and revised in 1963, and it is the most widely known and used system for preoperative risk assessment. ${ }^{1,11}$ The Helsinki ASA modification implemented approximately 2 decades ago was based on clinical observations and judgments by neuroanesthesiologists. Ever since, it has been used without a proper validation. Our study suggests that this call was justified, even though the precise criteria for the change are largely unknown. However, the modification takes into account some of the characteristics of the unique patient population in cranial neurosurgery, and these characteristics are embedded in the Helsinki ASA class but not in the original ASA class. Bearing in mind the original purpose of the ASA classification, the ASA class should perhaps be seen more as a representative of the burden of systemic disease at a given 
TABLE 6. Preoperative patient-related factors, routine blood tests, and LOS*

\begin{tabular}{|c|c|c|c|c|c|}
\hline Factor & $\begin{array}{c}\text { No. of } \\
\text { Patients }\end{array}$ & $\begin{array}{l}\text { LOS in } \\
\text { ICU }\end{array}$ & $p$ Value & $\begin{array}{l}\text { LOS in } \\
\text { hospital }\end{array}$ & $p$ Value \\
\hline Age (yrs) & 418 & & 0.303 & & $0.029 \dagger$ \\
\hline $18-47$ & 105 & 1.2 & & 4.9 & \\
\hline $48-58$ & 110 & 1.4 & & 5.3 & \\
\hline $59-65$ & 93 & 1.4 & & 6.3 & \\
\hline $66-87$ & 110 & 1.3 & & 4.9 & \\
\hline Sex & 418 & & 0.861 & & 0.496 \\
\hline Male & 158 & 1.4 & & 5.6 & \\
\hline Female & 126 & 1.3 & & 5.6 & \\
\hline Weight (kg) & 417 & & 0.145 & & 0.191 \\
\hline $40-64$ & 97 & 1.4 & & 6.0 & \\
\hline $65-74$ & 113 & 1.2 & & 5.4 & \\
\hline $75-86$ & 104 & 1.2 & & 5.6 & \\
\hline $87-164$ & 103 & 1.4 & & 5.4 & \\
\hline Height (cm) & 416 & & 0.667 & & 0.112 \\
\hline 148-162 & 115 & 1.4 & & 6.0 & \\
\hline $163-169$ & 96 & 1.2 & & 4.8 & \\
\hline $170-176$ & 102 & 1.2 & & 5.6 & \\
\hline $177-205$ & 103 & 1.5 & & 5.7 & \\
\hline $\mathrm{BMI}$ & 416 & & 0.406 & & 0.545 \\
\hline $16.4-23.4$ & 103 & 1.4 & & 5.9 & \\
\hline $23.5-25.7$ & 105 & 1.4 & & 5.8 & \\
\hline $25.8-29.0$ & 104 & 1.2 & & 5.3 & \\
\hline $29.1-47.4$ & 104 & 1.2 & & 5.2 & \\
\hline $\mathrm{SBP}(\mathrm{mm} \mathrm{Hg})$ & 416 & & 0.189 & & $0.029 \ddagger$ \\
\hline 95-128 & 106 & 1.1 & & 5.3 & \\
\hline $129-141$ & 103 & 1.3 & & 5.1 & \\
\hline $142-155$ & 105 & 1.2 & & 5.7 & \\
\hline $156-224$ & 102 & 1.5 & & 6.2 & \\
\hline $\mathrm{DBP}(\mathrm{mm} \mathrm{Hg})$ & 416 & & 0.556 & & 0.914 \\
\hline $46-78$ & 101 & 1.2 & & 5.4 & \\
\hline $79-86$ & 113 & 1.1 & & 5.6 & \\
\hline $87-93$ & 105 & 1.4 & & 5.7 & \\
\hline $94-137$ & 97 & 1.4 & & 5.6 & \\
\hline HR (per min) & 415 & & 0.343 & & 0.387 \\
\hline $41-60$ & 106 & 1.1 & & 5.7 & \\
\hline $61-68$ & 102 & 1.2 & & 5.6 & \\
\hline $69-78$ & 104 & 1.3 & & 5.7 & \\
\hline 79-114 & 103 & 1.5 & & 5.2 & \\
\hline $\mathrm{Hb}(\mathrm{g} / \mathrm{L})$ & 417 & & 0.317 & & $0.019 \S$ \\
\hline 105-133 & 108 & 1.4 & & 6.2 & \\
\hline $134-140$ & 100 & 1.2 & & 5.0 & \\
\hline $141-147$ & 104 & 1.3 & & 5.6 & \\
\hline $148-180$ & 105 & 1.3 & & 5.5 & \\
\hline
\end{tabular}

moment, not as a predictor of perioperative in-hospital neurological deficits. Our study results align with this view, as the preoperative Helsinki ASA score correlated with postoperatively recorded systemic and infectious
TABLE 6. Preoperative patient-related factors, routine blood tests, and LOS* (continued)

\begin{tabular}{|c|c|c|c|c|c|}
\hline Factor & $\begin{array}{c}\text { No. of } \\
\text { Patients }\end{array}$ & $\begin{array}{l}\text { LOS in } \\
\text { ICU }\end{array}$ & $p$ Value & $\begin{array}{l}\text { LOS in } \\
\text { hospital }\end{array}$ & $p$ Value \\
\hline Platelets (10\%/L) & 417 & & 0.416 & & 0.500 \\
\hline $32-201$ & 104 & 1.3 & & 5.8 & \\
\hline $202-238$ & 105 & 1.2 & & 5.5 & \\
\hline $239-285$ & 103 & 1.2 & & 5.4 & \\
\hline $286-543$ & 105 & 1.3 & & 5.6 & \\
\hline Crea $(\mu \mathrm{mol} / \mathrm{L})$ & 416 & & 0.143 & & 0.729 \\
\hline $5-59$ & 104 & 1.4 & & 5.6 & \\
\hline $60-68$ & 106 & 1.1 & & 5.7 & \\
\hline $69-77$ & 102 & 1.4 & & 5.7 & \\
\hline $78-160$ & 104 & 1.3 & & 5.4 & \\
\hline Gluc (mmol/L) & 409 & & $0.012 \pi$ & & 0.485 \\
\hline $3.9-5.3$ & 111 & 1.1 & & 5.7 & \\
\hline $5.4-5.7$ & 87 & 1.2 & & 5.5 & \\
\hline $5.8-6.6$ & 105 & 1.4 & & 5.6 & \\
\hline $6.7-24.8$ & 106 & 1.5 & & 5.5 & \\
\hline $\mathrm{Na}(\mathrm{mmol} / \mathrm{L})$ & 417 & & 0.117 & & 0.295 \\
\hline $123-136$ & 92 & 1.5 & & 6.5 & \\
\hline $137-139$ & 143 & 1.2 & & 5.2 & \\
\hline 140 & 56 & 1.4 & & 5.0 & \\
\hline $141-148$ & 126 & 1.3 & & 5.6 & \\
\hline $\mathrm{K}(\mathrm{mmol} / \mathrm{L})$ & 417 & & $0.025^{* *}$ & & 0.826 \\
\hline $2.9-3.7$ & 91 & 1.3 & & 5.2 & \\
\hline $3.8-3.9$ & 106 & 1.3 & & 6.0 & \\
\hline $4.0-4.1$ & 102 & 1.2 & & 5.1 & \\
\hline $4.2-5.6$ & 118 & 1.4 & & 5.9 & \\
\hline PT \% & 410 & & 0.746 & & 0.293 \\
\hline $9-96$ & 104 & 1.1 & & 4.9 & \\
\hline $97-108$ & 103 & 1.5 & & 6.3 & \\
\hline $109-128$ & 100 & 1.2 & & 5.5 & \\
\hline $129-170$ & 103 & 1.3 & & 5.7 & \\
\hline
\end{tabular}

* Continuous variables were divided into fourths (quartiles). CRP values could not be divided into fourths since three-fourths of the patients had normal CRP values $(\leq 3 \mathrm{mg} / \mathrm{l})$. The Kruskal-Wallis test was used to study differences between fourths. The post hoc Mann-Whitney test was used on each pair of significant groups. Values in boldface are statistically significant.

† Age group 4 (66-87 years) differed from age groups 1 (18-47 years; $p=$ 0.019 ) and 2 (48-58 years; $p=0.020$ ).

‡ SBP group 2 (129-141 mm Hg) differed from SBP group 4 (156-224 mm Hg; $p=0.004)$.

$\S \mathrm{Hb}$ group $1(105-133 \mathrm{~g} / \mathrm{L})$ differed from $\mathrm{Hb}$ groups $2(134-140 \mathrm{~g} / \mathrm{L} ; \mathrm{p}=$ $0.010)$ and $4(148-180 \mathrm{~g} / \mathrm{L} ; \mathrm{p}=0.013)$.

I Blood glucose level group $4(6.7-67.0 \mathrm{mmol} / \mathrm{L})$ differed from blood glucose level groups $1(3.9-5.3 \mathrm{mmol} / \mathrm{L} ; p=0.009)$ and $2(5.4-5.7 \mathrm{mmol} / \mathrm{L} ; p=0.020)$.

** Potassium level group $3(4.0-4.1 \mathrm{mmol} / \mathrm{L})$ differed from groups 1 (2.9-3.7 $\mathrm{mmol} / \mathrm{L} ; \mathrm{p}=0.033)$ and $4(4.2-5.6 \mathrm{mmol} / \mathrm{L} ; \mathrm{p}=0.003)$.

complications but not with new or worsening neurological deficits. Quantification of the systemic and infectious postoperative risks and making that quantification a part of surgical decision making may guide the selection of the safest treatment modality and resource allocation for an individual patient. For resource management, the use of 
TABLE 7. Various combinations of risk predictors and systemic and infectious complications

\begin{tabular}{|c|c|c|c|c|c|c|c|}
\hline Combinations & $\begin{array}{c}\text { No. of } \\
\text { Patients }\end{array}$ & OR $(95 \% \mathrm{Cl})$ & $\begin{array}{c}p \\
\text { Value* }\end{array}$ & PPV & NPV & Spec & Sens \\
\hline Combination 1: Helsinki ASA Class $4 \&$ age $\geq 60$ yrs & 44 & $3.93(1.62-9.57)$ & 0.001 & $18.2 \%$ & $94.7 \%$ & $90.8 \%$ & $28.6 \%$ \\
\hline $\begin{array}{l}\text { Combination 2: Helsinki ASA Class } 4, \& \text { age } \geq 60 \mathrm{yrs} \text {, } \\
\quad \& \text { CRP }>3 \mathrm{mg} / \mathrm{L}\end{array}$ & 17 & $4.82(1.46-15.91)$ & 0.005 & $23.5 \%$ & $94.0 \%$ & $96.7 \%$ & $14.3 \%$ \\
\hline Combination 3: Helsinki ASA Class 4 \& CRP $>3$ mg/L & 28 & $2.54(0.81-7.90)$ & 0.097 & $14.3 \%$ & $93.8 \%$ & $93.8 \%$ & $14.3 \%$ \\
\hline
\end{tabular}

a simple combination of preoperative factors can provide a tool to estimate the overall hospital costs for each patient. For example, the combination of Helsinki ASA Class 4 and age $\geq 60$ years carries an estimated extra cost of $€ 1500-€ 2800$ per patient during the in-hospital period at our institution. The combination of Helsinki ASA class, age, and CRP in risk prediction needs to be validated in a different cohort of elective craniotomy patients in the future. Combining Helsinki ASA Classes 1 and 2 may be appropriate, since only 4 patients (1\%) were classified as Helsinki ASA Class 1 in this study.

\section{Strengths and Weaknesses of the Study}

The study may have a few advantages. The study was based on assessments made by anesthesiologists, who apparently have no incentives to manipulate any of the study measures. In addition to the prospective study design, the broad inclusion criteria probably increase the external validity of the results: i.e., these results may be applicable to many Western neurosurgical units. There are also some limitations and drawbacks to this study. Regardless of its simplicity and wide applicability, the original ASA Physical Status Classification has been criticized for its considerable interrater variability. ${ }^{2,6,8}$ The Helsinki ASA classification may suffer from the same limitation. Most importantly, the Helsinki ASA system has not been validated previously, and therefore it may represent an insti-

TABLE 8. Various combinations of risk predictors and resource use

\begin{tabular}{lrcccc}
\hline Combination* & $\begin{array}{c}\text { No. of } \\
\text { Patients }\end{array}$ & $\begin{array}{c}\text { Mean ICU } \\
\text { LOS }\end{array}$ & $\begin{array}{c}p \\
\text { Value† }\end{array}$ & $\begin{array}{c}\text { Mean } \\
\text { Hospital } \\
\text { LOS }\end{array}$ & $\begin{array}{c}p \\
\text { Value† }\end{array}$ \\
\hline Combination 1 & & & $\mathbf{0 . 0 1 8}$ & & $\mathbf{0 . 0 0 4}$ \\
\hline Yes & 44 & 1.95 & & 6.86 & \\
\hline No & 374 & 1.22 & & 5.41 & \\
\hline Combination 2 & & & 0.164 & & 0.216 \\
\hline Yes & 17 & 2.12 & & 6.71 & \\
\hline No & 400 & 1.26 & & 5.52 & \\
\hline Combination 3 & & & 0.077 & & 0.135 \\
\hline Yes & 28 & 1.82 & & 6.25 & \\
\hline No & 389 & 1.26 & & 5.52 & \\
\hline
\end{tabular}

* Combination 1: Helsinki ASA Class 4 and age $\geq 60$ years; Combination 2: Helsinki $A S A=4$, age $\geq 60$ years, and CRP $>3 \mathrm{mg} / \mathrm{L}$; and Combination 3 : Helsinki ASA Class 4 and CRP $>3 \mathrm{mg} / \mathrm{L}$.

$\dagger$ Boldface indicates statistical significance. tution-specific phenomenon. Unfortunately, the scope of the study failed to include determining the interrater variability of the original or Helsinki ASA classifications, so we cannot exclude the possibility that the Helsinki ASA classification is subject to variability, or that it is institutionally biased. However, detailed instructions on determining both ASA classifications were implemented in the study protocol, and the Helsinki ASA classification is comparable to the original ASA classification in terms of its applicability in a clinical scenario. The study can also be criticized for being underpowered and susceptible to statistical errors. Our data were prospectively collected and tailored to the specific characteristics of intracranial neurosurgery and represent a full year's case mix at our institution. Moreover, the objective was not to evaluate the predictive value of single independent factors but rather to find a combination, i.e., a new widely applicable composite factor, which is associated with a greater risk of in-hospital complications. We aimed at simplicity in our statistical approach, but multivariable regression analyses were performed to supplement the analyses. As another possible drawback, patients' comorbidities were not included as possible contributors to outcome, similar to the previous registry-based study..$^{10}$ The main reason for excluding such data in the analyses was to increase the external validity of the results. In addition to highly varying incidences and prevalence, comorbidities, such as hypertension, myocardial disease, and renal insufficiency, are diagnosed and treated differently in different countries and institutions, and thus inclusion of these data would probably decrease the generalizability of the results. Furthermore, ASA classification indirectly includes the patient's comorbidity status. As our main purpose was to study the general applicability of various anesthesiological preoperative assessments in predicting in-hospital outcome, the use of perioperative surgical parameters (such as surgeon's experience, location of the lesion, preoperative diagnosis, surgical positions, and surgical time) as study inclusion criteria was deemed unnecessary. Furthermore, these factors are absent in previously published outcome scores. ${ }^{9}$ In addition, the presented predictors of outcome (i.e., the Helsinki ASA class, age, and CRP) are relatively objective and applicable in most Western countries with life expectancies similar to those in Finland. Finally, the low mortality and morbidity rates can perhaps be considered major drawbacks of our study, as statistical analyses on mortality-associated factors were unreliable, and no detailed subgroup analyses could be performed on the morbidity-related predictors. This may also have 
contributed to the fact that none of the factors assessed in this study predicted new neurological deficits.

\section{Conclusions}

Our results suggest that using a simple composite factor as a risk estimate of complications and resource use, health care professionals may be able to preoperatively identify patients requiring extra cautions and tailored care. Contrary to the traditional view that the location and nature of the lesion and the expertise of the surgeon determine the risk of an adverse outcome in brain surgery, our results suggest that it is possible to identify patients prone to systemic and infectious complications with simple preoperative assessments. Even though large registry-based studies are plausible also in Finland, a customized prospective study setting is imperative in establishing the value of preoperative factors in predicting postoperative complications. When such prospective studies are piloted in large neurosurgical centers, nationwide and international multicenter studies can be implemented to substantiate the findings. Thus, the results and morbidity rates presented here may perhaps serve as first objective benchmark numbers in the modern neurosurgical era and a guide to safeguarding good practice.

\section{Acknowledgment}

We would like to acknowledge Associate Professor Markus Skrifvars for his help in preparing the patient questionnaires and his expert advice on IBM SPSS software.

\section{References}

1. American Society of Anesthesiologists: New classification of physical status. Anesthesiology 24:111, 1963

2. Aronson WL, McAuliffe MS, Miller K: Variability in the American Society of Anesthesiologists Physical Status Classification Scale. AANA J 71:265-274, 2003

3. de Cássio Zequi S, de Campos ECR, Guimarães GC, Bachega W Jr, da Fonseca FP, Lopes A: The use of the American Society of Anesthesiology Classification as a prognostic factor in patients with renal cell carcinoma. Urol Int 84:67-72, 2010

4. Hightower CE, Riedel BJ, Feig BW, Morris GS, Ensor JE Jr, Woodruff VD, et al: A pilot study evaluating predictors of postoperative outcomes after major abdominal surgery: Physiological capacity compared with the ASA Physical Status Classification system. Br J Anaesth 104:465-471, 2010
5. Krell RW, Hozain A, Kao LS, Dimick JB: Reliability of risk-adjusted outcomes for profiling hospital surgical quality. JAMA Surg 149:467-474, 2014

6. Mak PH, Campbell RC, Irwin MG: The ASA Physical Status Classification: Inter-observer consistency. Anaesth Intensive Care 30:633-640, 2002

7. Nashef SAM, Roques F, Michel P, Gauducheau E, Lemeshow $\mathrm{S}$, Salamon R: European system for cardiac operative risk evaluation (EuroSCORE). Eur J Cardiothorac Surg 16:913, 1999

8. Ranta S, Hynynen M, Tammisto T: A survey of the ASA Physical Status Classification: significant variation in allocation among Finnish anaesthesiologists. Acta Anaesthesiol Scand 41:629-632, 1997

9. Reponen E, Tuominen H, Korja M: Evidence for the use of preoperative risk assessment scores in elective cranial neurosurgery: a systematic review of the literature. Anesth Analg 119:420-432, 2014

10. Rolston JD, Han SJ, Lau CY, Berger MS, Parsa AT: Frequency and predictors of complications in neurological surgery: national trends from 2006 to 2011. J Neurosurg 120:736745, 2014

11. Saklad M: Grading of patients for surgical procedures. Anesthesiology 2:281-284, 1941

\section{Author Contributions}

Conception and design: Reponen, Korja, Niemi, Tuominen. Acquisition of data: Reponen, Silvasti-Lundell, Tuominen. Analysis and interpretation of data: Reponen, Korja. Drafting the article: Reponen, Tuominen. Critically revising the article: Korja, Niemi, Silvasti-Lundell, Hernesniemi, Tuominen. Reviewed submitted version of manuscript: all authors. Approved the final version of the manuscript on behalf of all authors: Reponen. Statistical analysis: Reponen, Korja. Administrative/technical/ material support: Niemi, Hernesniemi. Study supervision: Korja, Niemi, Hernesniemi, Tuominen.

\section{Supplemental Information \\ Previous Presentation}

The results of this study were presented in part in abstract/poster form at Euroanaesthesia 2013 in Barcelona, Spain, June 4, 2013, and at the 32nd Scandinavian Society of Anaesthesiology and Intensive Care Medicine Congress in Turku, Finland, August 28, 2013.

\section{Correspondence}

Elina Reponen, Department of Anaesthesiology and Intesive Care Medicine, Helsinki University Central Hospital, P.O. Box 900, Helsinki 00029 HUS, Finland. email: elina.reponen@hus.fi. 